\title{
HUBUNGAN STRES DENGAN KUALITAS TIDUR PADA MAHASISWA TINGKAT AKHIR
}

\author{
Tri Okta Ratnaningtyas, Dwi Fitriani \\ Sekolah Tinggi Ilmu Kesehatan Kharisma Persada \\ Tangerang Selatan, 15417 \\ E-mail:triokta@masda.ac.id
}

\begin{abstract}
ABSTRAK
Mahasiswa merupakan salah satu kelompok dewasa awal yang memiliki banyak aktivitas, sehingga mahasiswa menjadi kelompok yang berisiko memiliki kualitas tidur yang buruk. Salah satu penyebab kualitas tidur yang buruk yaitu faktor stres. Penelitian ini dilakukan untuk mengidentifikasi hubungan stres dengan kualitas tidur pada mahasiswa tingkat akhir di STIKes Kharisma Persada. Penelitian ini menggunakan jenis penelitian observasional analitik dengan pendekatan kuantitatif dan desain cross sectional. Populasi dalam penelitian ini adalah seluruh mahasiswa tingkat akhir STIKes Kharisma Persada yang berjumlah 203 orang. Sampel dalam penelitian ini sebesar 133 responden yang diambil dengan teknik sampling yaitu simple random sampling. Pengumpulan data menggunakan kuesioner dan analisa data menggunakan uji statistik chi square. Berdasarkan hasil penelitian menunjukkan sebagian besar responden berusia 21 tahun dan berjenis kelamin perempuan. Berdasarkan hasil analisis univariat terhadap variabel stres diketahui sebagian besar responden yang mengalami stres memiliki kesulitan untuk relaks pada tingkat yang ringan dan sebagian besar responden mengalami stres dengan reaksi yang berlebih pada tingkat sedang. Sedangkan, hasil analisis univariat terhadap variabel kualitas tidur diketahui bahwa sebagian besar responden memiliki kualitas tidur yang baik berdasarkan aspek kualitas tidur subyektif, latensi tidur, durasi tidur, efisiensi tidur, gangguan tidur, dan penggunaan obat tidur serta sebagian besar responden memiliki kualitas tidur yang sedang berdasarkan aspek gangguan beraktivitas. Berdasarkan analisis bivariat dengan uji chi square diketahui ada hubungan stres dengan kualitas tidur dengan $p$ value $=0,016$. Ada hubungan antara stres dengan kualitas tidur pada mahasiswa tingkat akhir.
\end{abstract}

Kata kunci: stress, kualitas tidur, mahasiswa tingkat akhir.

\section{ABSTRACT}

Students are one of the early adult groups who have a lot of activities, so that students become a group at risk of having poor sleep quality. One of the causes of poor sleep quality is due to stress factor. This research was conducted to identify the relationship of stress with sleep quality in the final level students at STIKes Kharisma Persada. This research used analytic observational research with quantitative approach and cross sectional design. Population in this research were all final level students of STIKes Kharisma Persada, totaling 203 people. Sample in this research was 133 respondents were taken by sampling technique that is simple random sampling. Data collection using questionnaires and data analysis using chi square statistical tests. Based on the results of this research showed the majority of respondents aged are 21 years and female sex. Based on the results of univariate analysis of stress variables, it is known that most respondents who experience stress have difficulty relaxing at a mild level and most respondents experience stress with excessive reactions at moderate levels. Meanwhile, the results of univariate analysis of sleep quality variables are known that most respondents have good sleep quality based on aspects of subjective sleep quality, sleep latency, sleep duration, sleep efficiency, sleep disorders, and use of sleeping drugs and most of the respondents have moderate sleep quality based on the aspect of activity interruption. Based on bivariate analysis with chi square test, it is known that there is a relationship between stress and sleep quality with $p$ value $=0.016$. There is a relationship between stress and sleep quality in final level students.

Keywords: stress, sleep quality, final level student. 


\section{PENDAHULUAN}

Tidur merupakan salah satu kebutuhan dasar setiap manusia. Henderson memasukkan tidur dan istirahat ke dalam daftar empat belas kebutuhan dasar manusia. Adapun empat belas kebutuhan dasar manusia itu yaitu pernapasan, kebutuhan makan dan minum, eliminasi, positioning, kebutuhan tidur dan istirahat, kebutuhan dalam berpakaian, cara mempertahankan suhu tubuh dan memodifikasi lingkungan, kebersihan tubuh, kondisi lingkungan, komunikasi, ibadah dan keyakinan, pekerjaan seharihari, kebutuhan bermain dan rekreasi, serta kebutuhan belajar dan menggunakan fasilitas kesehatan (Wilkinsons dan Treas, 2011).

Kebutuhan akan tidur merupakan kebutuhan dasar setiap manusia. Oleh karena itu, tidur harus terpenuhi sesuai kebutuhan individu mengingat kebutuhan tidur setiap individu berbeda. Stores (2009) mengatakan bahwa seorang dewasa awal seharusnya memiliki total jam tidur per hari 7 sampai 8 jam untuk memperoleh fungsi kepuasan tidur. Akan tetapi, banyak kelompok dewasa awal yang kebutuhan tidurnya tidak terpenuhi secara maksimal. Hal ini dikarenakan faktor gaya hidup, baik tuntutan pekerjaan atau kegiatan sosial.

Lemma, Gelaye, Berhane, Worku, dan Williams pada tahun 2012 melakukan penelitian yang berjudul "Sleep Quality and Its Psychological Correlates Among University Students in Ethiopia". Responden dalam penelitian tersebut adalah semua mahasiswa kecuali mahasiswa tingkat pertama dan berjumlah 2551 orang. Instrumen yang digunakan pada penelitian tersebut yaitu Pittsburgh Sleep Quality Index (PSQI) untuk mengkaji kualitas tidur dan Depression Anxiety Stress Scale (DASS) untuk mengkaji gejala stres, kecemasan, dan depresi.

Berdasarkan penelitian yang dilakukan Lemma, Gelaye, Berhane, Worku, dan Williams (2012) diperoleh hasil $0,8 \%$ (1.294) mahasiswa memiliki gejala depresi, 58\% (1.369) mahasiswa memiliki gejala kecemasan, dan $34,1 \%$ (864) mahasiswa memiliki gejala stress, serta $55,8 \% \quad(1.424) \quad$ mahasiswa memiliki kualitas tidur buruk. Jika dibandingkan dengan mahasiswa tingkat 4, mahasiswa tingkat 2 memiliki 
kemungkinan 2,91 kali mengalami kualitas tidur yang buruk, mahasiswa tingkat 3 memiliki kemungkinan 2,10 kali mengalami kualitas tidur yang buruk, dan mahasiswa tingkat 3 memiliki kemungkinan 2,25 kali mengalami kualitas tidur yang buruk. Menurut data International of sleep disorder, prevalensi penyebab gangguan tidur adalah gelisah (5 sampai $15 \%)$, ketergantungan alkohol (10\%), terlambat tidur $(10 \%)$, perubahan jadwal (2 sampai 5\%), penyakit $(<1 \%)$ dan stres (65\%) (Handayani dalam Wahyuni, 2016).

Stres merupakan salah satu penyebab dari gangguan tidur karena pada saat stres terjadi peningkatan

\section{METODE}

Penelitian ini menggunakan jenis penelitian observasional analitik dengan pendekatan kuantitatif. Desain studi dalam penelitian ini adalah cross sectional. Populasi yang digunakan dalam penelitian ini adalah seluruh mahasiswa tingkat akhir program studi D3 Farmasi, D3 Rekam Medis dan Informasi Kesehatan serta S1 Kesehatan Masyarakat STIKes Kharisma Persada yang berjumlah 203 orang. Sampel dalam hormon epinefrin, norepinefrin, dan kortisol yang mempengaruhi susunan saraf pusat dan menimbulkan keadaan terjaga dan meningkatkan kewaspadaan sistem saraf pusat. Hal ini juga dapat mempengaruhi kualitas tidur individu. Selain itu, perubahan hormon tersebut juga mempengaruhi siklus tidur Non Rapid Eye Movement (NREM) dan Rapid Eye Movement (REM) sehingga dapat membuat orang sering terbangun pada malam hari dan bermimpi buruk (Sherwood, 2011). Berdasarkan uraian di atas, maka peneliti tertarik untuk melakukan penelitian yang berjudul "Hubungan Stres dengan Kualitas Tidur pada Mahasiswa Tingkat Akhir di STIKes Kharisma Persada Tahun 2019”.

penelitian ini berjumlah 133 mahasiswa yang diambil dengan menggunakan teknik sampling yaitu simple random sampling. Pengumpulan data dalam penelitian ini menggunakan kuesioner dan analisa data menggunakan uji statistik chi square. Penelitian ini dilaksanakan di STIKes Kharisma Persada yang berlokasi di Jalan Pajajaran No. 1, Pamulang, Kota Tangerang Selatan Provinsi Banten. Penelitian ini dilaksanakan selama dua 
bulan mulai bulan April 2019 sampai dengan bulan Mei 2019.

\section{HASIL}

\section{Hasil Analisis Univariat}

\section{a. Karakteristik Responden}

Karakteristik responden pada jenis kelamin sebagaimana

penelitian ini meliputi usia dan dijelaskan pada tabel di bawah ini:

Tabel 1. Distribusi Frekuensi Karakteristik Responden Berdasarkan Usia dan Jenis Kelamin

\begin{tabular}{llcc}
\hline No. & \multicolumn{1}{c}{$\begin{array}{c}\text { Karakteristik } \\
\text { Responden }\end{array}$} & $\begin{array}{c}\text { Jumlah } \\
\text { (f) }\end{array}$ & $\begin{array}{c}\text { Persentase } \\
(\mathbf{\%})\end{array}$ \\
\hline 1. & Usia & & \\
& a. 19 tahun & 1 & 0,8 \\
b. 20 tahun & 29 & 21,8 \\
c. 21 tahun & 63 & 47,4 \\
d. 22 tahun & 31 & 23,3 \\
e. 23 tahun & 5 & 3,8 \\
f. 24 tahun & 2 & 1,5 \\
g. 25 tahun & 2 & 1,5 \\
\hline & Total & $\mathbf{1 3 3}$ & $\mathbf{1 0 0 , 0}$ \\
\hline 2. Jenis Kelamin & & 15,8 \\
& a. Laki-Laki & 21 & 84,2 \\
\hline b. Perempuan & 112 & $\mathbf{1 0 0 , 0}$ \\
\hline
\end{tabular}

Sumber: Data Primer, 2019

Berdasarkan distribusi frekuensi

karakteristik responden yang telah

dijelaskan dalam tabel 1 diketahui

bahwa sebagian besar responden

berusia 21 tahun yaitu sebesar 63

responden dengan persentase

\section{b. Stres}

Faktor stres pada penelitian ini meliputi kesulitan untuk relaks dan
47,4\% dan sebagian besar responden berjenis kelamin perempuan yaitu sebesar 112 responden dengan persentase $84,2 \%$.

reaksi yang berlebih sebagaimana dijelaskan pada tabel berikut ini: 
Tabel 2. Distribusi Frekuensi Stres Berdasarkan Kesulitan untuk Relaks dan Reaksi yang Berlebih

\begin{tabular}{|c|c|c|c|}
\hline No. & Stres & $\begin{array}{l}\text { Jumlah } \\
\text { (f) }\end{array}$ & $\begin{array}{c}\text { Persentase } \\
(\%)\end{array}$ \\
\hline \multicolumn{4}{|c|}{ 1. Kesulitan untuk Relaks } \\
\hline & a. Ringan & 64 & 48,1 \\
\hline & b. Sedang & 53 & 39,9 \\
\hline & c. Berat & 16 & 12,0 \\
\hline \multicolumn{2}{|r|}{ Total } & 133 & $\mathbf{1 0 0 , 0}$ \\
\hline \multirow[t]{4}{*}{2.} & \multicolumn{3}{|l|}{ Reaksi yang Berlebih } \\
\hline & a. Ringan & 43 & 32,3 \\
\hline & b. Sedang & 81 & 60,9 \\
\hline & c. Berat & 9 & 6,8 \\
\hline \multicolumn{2}{|r|}{ Total } & 133 & 100,0 \\
\hline
\end{tabular}

Sumber: Data Primer, 2019

Berdasarkan distribusi frekuensi stres yang telah dijelaskan dalam tabel 2 diketahui bahwa sebagian besar responden yang mengalami stres memiliki kesulitan untuk relaks pada tingkat yang ringan yaitu sebesar 64 responden dengan persentase $48,1 \%$ dan sebagian besar responden mengalami stres dengan reaksi yang berlebih pada tingkat sedang yaitu sebesar 81 responden dengan persentase $60,9 \%$.

\section{c. Kualitas Tidur}

Kualitas tidur pada penelitian ini meliputi aspek kualitas tidur subyektif, latensi tidur, durasi tidur, efisiensi tidur, gangguan

tidur, penggunaan obat tidur, dan gangguan beraktivitas sebagaimana dijelaskan pada tabel berikut ini:

Tabel 3. Distribusi Frekuensi Kualitas Tidur Berdasarkan Kualitas Tidur Subyektif, Latensi Tidur, Durasi Tidur, Efisiensi Tidur, Gangguan Tidur, Penggunaan Obat

Tidur, dan Gangguan Beraktivitas

\begin{tabular}{|c|c|c|c|}
\hline No. & Kualitas Tidur & $\begin{array}{c}\text { Jumlah } \\
\text { (f) }\end{array}$ & $\begin{array}{c}\text { Persentase } \\
(\%)\end{array}$ \\
\hline \multicolumn{4}{|c|}{ 1. $\quad$ Kualitas Tidur Subyektif } \\
\hline & a. Baik & 85 & 63,9 \\
\hline & b. Sedang & 36 & 27,1 \\
\hline & c. Buruk & 12 & 9,0 \\
\hline \multicolumn{2}{|r|}{ Total } & 133 & 100,0 \\
\hline
\end{tabular}




\begin{tabular}{|c|c|c|c|}
\hline No. & Kualitas Tidur & $\begin{array}{c}\text { Jumlah } \\
\text { (f) }\end{array}$ & $\begin{array}{c}\text { Persentase } \\
(\%)\end{array}$ \\
\hline \multicolumn{4}{|c|}{ Latensi Tidur } \\
\hline & a. Baik & 97 & 72,9 \\
\hline & b. Sedang & 36 & 27,1 \\
\hline & c. Buruk & 0 & 0,0 \\
\hline \multicolumn{2}{|r|}{ Total } & 133 & 100,0 \\
\hline \multirow[t]{5}{*}{3.} & Durasi Tidur & & \\
\hline & a. Baik & 60 & 45,1 \\
\hline & b. Sedang & 31 & 23,3 \\
\hline & c. Buruk & 42 & 31,6 \\
\hline & Total & 133 & 100,0 \\
\hline \multicolumn{4}{|c|}{ Efisiensi Tidur } \\
\hline & a. Baik & 84 & 63,2 \\
\hline & b. Sedang & 15 & 11,3 \\
\hline & c. Buruk & 34 & 25,5 \\
\hline \multicolumn{2}{|r|}{ Total } & 133 & 100,0 \\
\hline \multirow[t]{5}{*}{5.} & Gangguan Tidur & & \\
\hline & a. Baik & 82 & 61,7 \\
\hline & b. Sedang & 51 & 38,3 \\
\hline & c. Buruk & 0 & 0,0 \\
\hline & Total & 133 & 100,0 \\
\hline \multirow[t]{5}{*}{6.} & Penggunaan Obat Tidur & & \\
\hline & a. Baik & 130 & 97,7 \\
\hline & b. Sedang & 3 & 2,3 \\
\hline & c. Buruk & 0 & 0,0 \\
\hline & Total & 133 & 100,0 \\
\hline \multirow[t]{5}{*}{7.} & Gangguan Beraktivitas & & \\
\hline & a. Baik & 53 & 39,8 \\
\hline & b. Sedang & 77 & 57,9 \\
\hline & c. Buruk & 3 & 2,3 \\
\hline & Total & 133 & 100,0 \\
\hline
\end{tabular}

Sumber: Data Primer, 2019

Berdasarkan distribusi frekuensi kualitas tidur yang telah dijelaskan dalam tabel 3 diketahui bahwa sebagian besar responden memiliki kualitas tidur dengan tingkat kualitas tidur subyektif yang baik yaitu sebesar 85 responden dengan persentase 63,9\%; sebagian besar responden memiliki kualitas tidur dengan tingkat latensi tidur yang baik yaitu sebesar 97 responden dengan persentase 72,9\%; sebagian besar responden memiliki kualitas tidur dengan tingkat durasi tidur yang baik yaitu sebesar 60 responden dengan persentase $45,1 \%$; sebagian besar responden 
memiliki kualitas tidur dengan tingkat efisiensi tidur yang baik yaitu sebesar 84 responden dengan persentase $63,2 \%$; sebagian besar responden memiliki kualitas tidur dengan tingkat gangguan tidur yang baik yaitu sebesar 82 responden dengan persentase $61,7 \%$; sebagian besar responden memiliki kualitas tidur dengan tingkat penggunaan obat tidur yang baik yaitu sebesar 130 responden dengan persentase 97,7\%; dan sebagian besar responden memiliki kualitas tidur dengan tingkat gangguan beraktivitas sedang yaitu sebesar 77 responden dengan persentase $57,9 \%$.

\section{Hasil Analisis Bivariat}

\section{Hubungan Stres dengan Kualitas}

\section{Tidur}

Hubungan stress dengan kualitas

di bawah ini:

tidur dapat dijelaskan dalam tabel 4

Tabel 4. Hasil Analisis Hubungan Stres dengan Kualitas Tidur

\begin{tabular}{|c|c|c|c|c|c|c|c|}
\hline \multirow{3}{*}{ Stres } & \multicolumn{4}{|c|}{ Kualitas Tidur } & \multirow{2}{*}{\multicolumn{2}{|c|}{ Total }} & \multirow{3}{*}{$P$ Value } \\
\hline & \multicolumn{2}{|c|}{ Baik } & \multicolumn{2}{|c|}{ Buruk } & & & \\
\hline & f & $\%$ & f & $\%$ & f & $\%$ & \\
\hline Ringan & 6 & 22,2 & 21 & 77,8 & 27 & 100,0 & 0,016 \\
\hline Berat & 6 & 5,7 & 100 & 94,3 & 106 & 100,0 & 0,010 \\
\hline
\end{tabular}

Sumber: Data Primer, 2019

Berdasarkan tabel 4 di atas diketahui

bahwa responden yang mengalami stres pada tingkat ringan memiliki kualitas tidur yang buruk yaitu sebesar 21 dari 27 responden (77,8\%), begitu juga dengan responden yang mengalami stres pada tingkat berat memiliki kualitas tidur yang buruk yaitu sebesar 100 dari
106 responden (94,3\%). Menurut tabel 4 juga dapat diketahui bahwa berdasarkan hasil uji statistik diperoleh $P$ Value sebesar 0,016 dimana nilai tersebut kurang dari $\alpha=$ 0,05, maka hal ini menunjukkan bahwa ada hubungan yang bermakna antara stres dengan kualitas tidur pada mahasiswa tingkat akhir. 


\section{DISKUSI}

\section{Hubungan Stres dengan Kualitas Tidur}

a. Stres

Menurut teori Lukaningsih dan Bandiyah (2011), stres merupakan respon tubuh yang bersifat tidak spesifik terhadap setiap tuntutan atau beban kerja. Seseorang yang mengalami stres akan timbul gejalagejala seperti sakit kepala, mudah marah, penurunan berat badan, gelisah atau kecemasan yang berlebihan, sulit tidur, dan sulit berkonsentrasi. Stres dapat disebabkan oleh beberapa faktor seperti: keuangan, kelelahan fisik, pekerjaan, dan kegagalan mencapai sesuatu yang diinginkan.

Berdasarkan hasil uji statistik yang dilakukan menggunakan uji chi square diketahui bahwa responden yang mengalami stres pada tingkat ringan memiliki kualitas tidur yang buruk yaitu sebesar 21 dari 27 responden $(77,8 \%)$, begitu juga dengan responden yang mengalami

\section{b. Kualitas Tidur}

Menurut teori Lemma et.al (2012), kualitas tidur dilihat melalui dua aspek yaitu aspek kualitatif dan aspek kuantitatif. Aspek kuantitatif meliputi stres pada tingkat berat memiliki kualitas tidur yang buruk yaitu sebesar 100 dari 106 responden $(94,3 \%)$. Selain itu, berdasarkan hasil uji statistik diperoleh $P$ Value sebesar 0,016 dimana nilai tersebut kurang dari $\alpha=0,05$, hal ini menunjukkan bahwa ada hubungan yang bermakna antara stres dengan kualitas tidur pada mahasiswa tingkat akhir. Hasil penelitian ini sejalan dengan yang dilakukan oleh Simbolan (2012) yang menunjukkan bahwa responden yang mengalami stres ringan sebanyak 62 orang $(30,7 \%)$, stres sedang sebanyak 137 orang $(60,8 \%)$, dan stres berat sebanyak 3 orang (1,5\%). Mahasiswa yang mengalami stres dapat disebabkan karena tuntutan akademik, seperti tuntutan banyaknya tugas terutama penyusunan tugas akhir yang harus diselesaikan dengan waktu yang telah ditentukan oleh pihak kampus.

lamanya waktu tidur, sedangkan aspek kualitatif merupakan aspek subjektif dari kedalaman tidur dan perasaan segar pada saat terjaga. 
Berdasarkan hasil uji statistik menggunakan uji chi square diketahui sebanyak 121 responden dengan persentase $91,0 \%$ memiliki kualitas tidur buruk, dan sebanyak 12 responden dengan persentase $9,0 \%$ memiliki kualitas tidur baik.

Hasil penelitian ini sejalan dengan penelitian yang dilakukan oleh Leni Tri Wahyuni pada tahun 2016 yang menunjukkan bahwa sebanyak 38 mahasiswa dengan persentase $82,6 \%$ memiliki kualitas tidur buruk dan 8 mahasiswa dengan persentase $17,4 \%$

\section{c. Hubungan Stres dengan Kualitas Tidur}

Menurut teori Sherwood (2011), pada saat stres terjadi peningkatan hormon epinefrin, norepinefrin, dan kortisol yang mempengaruhi susunan saraf pusat sehingga menimbulkan keadaan terjaga dan meningkatkan kewaspadaan pada sistem saraf pusat. Hal ini dapat mempengaruhi kualitas tidur individu. Selain itu perubahan hormon tersebut juga mempengaruhi siklus tidur Non Rapid Eye Movement (NREM) dan Rapid Eye Movement (REM) sehingga dapat membuat memiliki kualitas tidur baik. Mahasiswa yang memiliki kualitas tidur buruk dapat disebabkan karena mahasiswa harus menyelesaikan tugas-tugas yang diberikan oleh dosen. Dengan demikian, agar mahasiswa dapat menyelesaikan tugas sesuai dengan waktu yang telah ditentukan, maka mengakibatkan mahasiswa yang bersangkutan sering tidur larut malam yang membuat mahasiswa tersebut perlu untuk merubah pola tidurnya.

orang sering terbangun pada malam hari dan bermimpi buruk.

Berdasarkan hasil uji statistik yang dilakukan menggunakan uji chi square diketahui responden yang mengalami stres pada tingkat ringan memiliki kualitas tidur yang buruk yaitu sebesar 21 dari 27 responden $(77,8 \%)$, begitu juga dengan responden yang mengalami stres pada tingkat berat memiliki kualitas tidur yang buruk yaitu sebesar 100 dari 106 responden (94,3\%). Selain itu, berdasarkan hasil uji statistik 
diperoleh $P$ Value sebesar 0,016 dimana nilai tersebut kurang dari $\alpha=$ 0,05 , hal ini menunjukkan bahwa ada hubungan yang bermakna antara stres dengan kualitas tidur pada mahasiswa tingkat akhir. Hasil penelitian ini sejalan dengan penelitian yang dilakukan oleh Leni Tri Wahyuni pada tahun 2016 yang berjudul "Hubungan Stres dengan Kualitas Tidur Mahasiswa Profesi Keperawatan STIKes Ranah Minang Padang" yang menjelaskan bahwa terdapat hubungan antara stres dengan kualitas tidur. Berdasarkan hasil penelitian tersebut diketahui sebanyak 25 responden dengan

\section{SIMPULAN}

Berdasarkan hasil uji statistik diperoleh $P$ Value sebesar 0,016 dimana nilai tersebut kurang dari $\alpha=0,05$, hal ini menunjukkan bahwa ada hubungan yang

\section{DAFTAR PUSTAKA}

Lemma, S., et.al. 2012. Sleep quality and its psychological correlates among university students in Ethiopia: a cross-sectional study. Journal of BMC Psychiatry 12 (237).

Doi:10.1186/1471-244X-12-237. persentase $96,2 \%$ mengalami stres sedang dengan kualitas tidur yang buruk.

Mahasiswa yang terlalu keras dalam berpikir akan menimbulkan stres, sehingga mahasiswa akan sulit untuk mengontrol emosinya yang berdampak pada peningkatan ketegangan dan kesulitan dalam memulai waktu tidur. Perasaan tegang mahasiswa tersebut dapat menyebabkan mahasiswa sulit tidur atau sering terbangun saat tidur, sehingga akan mengganggu mahasiswa untuk mendapatkan kualitas tidur sesuai dengan yang diinginkan.

bermakna antara stres dengan kualitas tidur pada mahasiswa tingkat akhir.

Lukaningsih, Z. dan Bandiyah, S. 2011. Psikologi Kesehatan. Yoogyakarta: Nuhu Medika.

Sherwood, L. 2011. Fisiologi Manusia Edisi 2. Jakarta: EGC. 
Simbolan, D. 2012. Gambaran Stres Mahasiswa Sarjana Keperawatan Sumatera Utara.

Stores, G. 2009. Insomnia and other adult sleep problem. Oxford: Oxford University Press.

Wahyuni, L. T. 2016. Hubungan Stres dengan Kualitas Tidur Mahasiswa
Profesi Keperawatan STIKes Ranah Minang Padang Tahun 2016. Skripsi. Sumatera Barat: Universitas Muhammadiyah.

Wilkinsons, J.M. and Treas, L.S. 2011. Fundamental of nursing: Theory, concepts, and application (Vol. 1). Philadelphia: F.A. Davis Company. 